Valera, Eva. Los AAE entre la UE y África. La introducción de la reciprocidad y el caso de Ghana. http://dx.doi.org/10.5209/rev_PADE.2012.n24.39546

\title{
LOS AAE ENTRE LA UE Y ÁFRICA. LA INTRODUCCIÓN DE LA RECIPROCIDAD Y EL CASO DE GHANA
}

\section{The EPA BetWeen the EU AND AfRicA. The INTROdUction OF RECIPROCITY AND THE CASE OF GHANA}

\author{
Eva Valera Fernández ${ }^{1}$ \\ Universidad Complutense de Madrid \\ eva.valfer@gmail.com
}

Fecha recepción: 23 de marzo de 2011

Fecha aceptación: 9 de abril de 2012

\section{RESUMEN}

En el marco de los Acuerdos de Cotonú, la Unión Europea (UE) está negociando los Acuerdos de Asociación Económica (AAE) con las distintas regiones de los países de África, Caribe y Pacífico (ACP) en los que se introduce la reciprocidad comercial. Tomando el caso del AAE provisional que se pretende firmar este año 2011 entre la UE y Ghana, este trabajo describe y analiza las características del acuerdo y sus consecuencias para el país africano. También se critica la introducción prematura de la reciprocidad en el comercio entre ambas regiones.

Palabras ClaVe: Comercio, Acuerdos comerciales preferenciales, África, Unión Europea, Ghana, Reciprocidad.

JEL: F13, F14, F53.

\section{Abstract}

Under the Cotonou Agreement, the European Union (EU) is negotiating the Economic Partnership Agreements (EPA) with the different regions of the countries African, Caribbean and Pacific (ACP) where trade reciprocity is introduced. Taking the case of the provisional EPA that is meant to be signed between the EU and Ghana, this paper describes and analyzes the characteristics of the Agreement and its consequences for the African country. It also criticizes the premature introduction of the reciprocity in the trade between both regions.

KEY WORDS: Trade, Preferential trade agreements, Africa, European Union, Ghana, Reciprocity.

\footnotetext{
${ }^{1}$ Agradezco al profesor Javier Oyarzun su guía y ayuda a lo largo de los meses de realización de esta investigación. Asimismo, quisiera agradecer a los profesores Ángel Alañón, Rafael Fernández y Ma ${ }^{a}$ José Paz sus comentarios al texto realizados en la lectura de este trabajo en junio de 2010.
} 
Valera, Eva. Los AAE entre la UE y África. La introducción de la reciprocidad y el caso de Ghana.

\section{INTRODUCCIÓN}

Los países ACP (África-Caribe-Pacífico), agrupados por regiones geográficas, están negociando unos acuerdos bilaterales con la Unión Europea (UE). Estos se conocen como los Acuerdos de Asociación Económica (AAE), que están dentro del marco del Acuerdo de Cotonú. Los países ACP, a la vez que negocian con la UE, están inmersos en las negociaciones multilaterales de la Ronda de Doha, de la Organización Mundial del Comercio (OMC), así como en procesos de integración regional.

El avance en la liberalización comercial, que es la piedra angular de los AAE, se justifica teóricamente por la supuesta condición necesaria para el desarrollo que cumple la apertura comercial. Por otro lado, sería necesaria en el contexto de la OMC, que pretende acabar con la no-reciprocidad entre las distintas partes que comercian y que no formen un acuerdo de integración.

Sin embargo, esto no es del todo cierto. Las economías africanas son ya altamente extravertidas. A partir de los años 80 , dos décadas después de las primeras independencias, las políticas de ajuste neoliberal promovidas por el Banco Mundial (BM) y recogidas en el conocido Informe Berg de 1981 fomentaron la completa liberalización de sus economías, como contrapartida al acceso a financiación exterior con la cual poder hacer frente a los desequilibrios macroeconómicos y al sobre-endeudamiento que sufrían algunos países africanos. El pensamiento ortodoxo, que presupone que el derribo de barreras al comercio reporta ganancias para el desarrollo, parte de "la base de una completa movilidad de recursos productivos en respuesta a las señales de tipo económico y a las oportunidades que se puedan presentar. En el mundo actual, sin embargo, no suele ocurrir que tanto los capitales como las personas estén plenamente empleados"2.

El punto de partida de este trabajo es que la no reciprocidad en los intercambios comerciales entre los países desarrollados (PD) y los países en desarrollo (PED) sigue vigente legalmente, aunque se trate de reducir su implementación. Si los AAE introducen la reciprocidad es por voluntad de la UE (debido principalmente a la pérdida de importancia como origen de las importaciones de los países ACP), no por imposición de la OMC.

Mi interés se centra en el continente africano, y por ello (y porque es uno de los pocos países se han comprometido a firmar un AAE, aunque sea provisional) he escogido el caso de Ghana. Haré especial énfasis en el comercio de productos agrícolas, por ser éste uno de los principales sectores de exportación de los países africanos y a la vez uno de los más protegidos en el mercado europeo, pero siempre en el contexto del comercio global.

El trabajo se divide en dos partes. La primera trata de la descripción de los Sistema Generalizados de Preferencias (punto primero), con especial atención a los europeos (punto segundo), para luego entrar en los Acuerdos de Lomé y Cotonú (tercero). En el cuarto punto de esta primera parte se tratan los

\footnotetext{
${ }^{2}$ Houck y Briz, 2004
} 
Valera, Eva. Los AAE entre la UE y África. La introducción de la reciprocidad y el caso de Ghana.

acuerdos de la UE con África, para pasar al AAE provisional (o interino) que se va a firmar en 2011 con Ghana. La segunda parte trata de hacer un análisis de los acuerdos descritos, así como una crítica al modelo. Para ello, en primer lugar se repasan las características del comercio entre la UE y Ghana y seguidamente se analizan los (posibles) efectos positivos y negativos del AAE para la economía de Ghana. En el cuarto punto de esta segunda parte se hace una breve crítica a la liberalización comercial como vía hacia el crecimiento económico, que se relaciona con el punto quinto, que debate también brevemente sobre la necesidad de introducir el principio de reciprocidad en los AAE. Después de hacer una crítica al proteccionismo de la agricultura europea se repasan algunas opiniones generales en contra de la firma de estos acuerdos. Se finaliza con unas breves conclusiones.

\section{DESCRIPCIÓN DE LOS SISTEMAS DE PREFERENCIAS Y ACUERDOS COMERCIALES. LA UE CON ÁFRICA Y EL CASO DE GHANA}

\subsection{Los Sistemas Generalizados de Preferencias}

En 1947 se creó el GATT (General Agreement on Trade and Tariffs) como acuerdo regulatorio de los aranceles y del comercio internacional. Constaba de veinticinco artículos agrupados en tres categorías: principios, normas que deben regir el comercio internacional y materias diversas. Fueron 23 los países que firmaron el GATT en ese año, mientras que hoy son 153 los integrantes de la OMC.

Dentro de los principios del GATT encontramos el de no discriminación, que a su vez consta de dos normas principales: la Cláusula de Nación Más Favorecida (NMF) (art. I) y el Trato Nacional (art. III), y el principio de reciprocidad, por el cual el país que se beneficia de una reducción arancelaria por parte de otro país miembro debe, a su vez, corresponder con reducciones arancelarias "sustancialmente equivalentes"3 (Oyarzun, 1993). Asimismo, se introducía el art. XXIV, por el cual los países o regiones que formen una Unión Aduanera (UA) o un Área de Libre Comercio (ALC) quedaban eximidos de la observancia del principio de NMF.

A partir de los años 50, y principalmente los 60 , se fueron sumando nuevos países, muchos de ellos PED, que tenían una estructura comercial diferenciada de los PD. En ese momento se hace evidente que las partes contratantes (según terminología del GATT) no pueden ser tratadas como iguales, porque no lo son.

En 1955 el GATT aceptaba la necesidad de tratar de manera especial a los PED para facilitar el crecimiento y desarrollo económico ${ }^{4}$, y en 1964 el

\footnotetext{
${ }^{3}$ La necesidad de combinar ambos principios viene del riesgo de existencia de países "freeriders", que son los países que se beneficiarían de las concesiones comerciales de los demás según el principio de NMF, pero no responderían con una reducción arancelaria equivalente. Por ello es necesario combinar NFM y reciprocidad (Oyarzun, 1998).

${ }^{4}$ Art. XVIII del GATT recoge los países con bajo nivel de vida y en las primeras fases de su desarrollo podrán modificar o retirar concesiones arancelarias acordadas, usar restricciones cuantitativas para proteger la Balanza de Pagos y, que los PED pueden, sujeto a notificación,
} 
Valera, Eva. Los AAE entre la UE y África. La introducción de la reciprocidad y el caso de Ghana.

Secretario General de la UNCTAD, Raúl Prebisch, propuso la creación de un sistema no-recíproco de preferencias arancelarias para los PED ("reciprocidad real" frente a la "reciprocidad formal", como señalaba Prebisch). Por todo ello, en ese año se añadía una cuarta parte al GATT que constaba de tres artículos (del XXXVI al XXXVIII). En esta parte se consagra el principio de noreciprocidad en las relaciones comerciales: "las partes contratantes desarrolladas no esperan obtener reciprocidad por los compromisos contraídos por ellas en las negociaciones comerciales para reducir o suprimir los derechos de aduana y otros obstáculos de las partes contratantes poco desarrolladas".

En este contexto se establecen, en 1968, los Sistemas Generalizados de Preferencias (SGP), que se definieron como sistemas no-recíprocos y discriminatorios. Para poder implantar estos sistemas fue necesario que el GATT eximiera a los PD de la obligación de no discriminación bajo NMF y del principio de reciprocidad, algo que se consiguió de manera provisional en 1971 y ya de forma permanente en 1979 (Cláusula de Habilitación del GATT).

Los SGP están diseñados bajo el razonamiento siguiente: cuando un país incrementa sus exportaciones, el crecimiento económico de ese país aumenta mediante incentivos al aumento de la producción, lo que a largo plazo supone más inversión para aumentar la capacidad de la industria exportadora y para crear nueva industria, lo que a su vez significará la adopción de nuevas tecnologías y mejor organización del trabajo. Todo ello resultará en más y mejor industrialización, diversificación, aprovechamiento de economías de escala, más y mejores oportunidades de trabajo, incremento de la productividad y, por último, la transformación en un país de mayores ingresos. En palabras de Raúl Prebisch: "El trato preferencial a las exportaciones de los países en desarrollo [...] ayudará a las industrias de [esos] países a superar las dificultades que enfrentan en los mercados de exportaciones debido a sus altos costes" (Prebisch, 1964). Cabe decir que Prebisch tuvo muchos problemas por defender estas tesis, ya que encontraba la oposición de varios países africanos que todavía mantenían las antiguas preferencias coloniales, y a los que criticaba por no llevar a cabo las reformas fiscales, financieras y comerciales que creía necesarias (Dosman, 2006).

Algunos productos no entran en los sistemas de preferencias ya que o bien son competencia de un sector protegido en el país desarrollado (PD), o porque ya gozan de arancel 0 en la lógica NMF. Para otros productos, sin embargo, estas preferencias constituyen una gran diferencia.

A pesar de la intención de desarrollo del sector exportador de los SGP, los países que más se suelen beneficiar de este sistema son aquellos que ya contaban con una capacidad productiva y exportadora suficientemente grande previa a la firma del SPG. Por ejemplo, en el año 2002, las exportaciones de los 44 países PMA (País Menos Adelantado) que se podían beneficiar de las preferencias representaron tan solo el $13,5 \%$ de las importaciones totales

previa consulta y, en algunos casos, con la concurrencia de las partes contratantes, utilizar cualquier medida que no fuese consistente con otras estipulaciones del GATT con el propósito de promover una industria específica. 
Valera, Eva. Los AAE entre la UE y África. La introducción de la reciprocidad y el caso de Ghana.

europeas bajo SPG, mostrando además un elevado grado de concentración en pocos países.

Además, la evidencia nos enseña que muchos países acaban dependiendo de la exportación de uno o pocos productos. Esto es negativo en el sentido de que:

1) dependerán en gran medida de la evolución de los precios a nivel mundial;

2) en el momento en el que entren más países a competir con sus productos (por la progresiva reducción arancelaria bajo el paraguas de la NMF) tendrán dificultades para seguir manteniendo la cuota de mercado de estas mono-exportaciones, lo que significará una fuerte caída de sus ingresos por erosión de los márgenes de preferencia. Cuanto mayores sean estas reducciones arancelarias, menores serán los efectos conseguidos con los SPG.

Por último, aunque la liberalización arancelaria es importante para incentivar el comercio internacional, existen otras barreras a la entrada impuestas por los PD, como los requisitos administrativos y las normas de origen, entre otros.

A nivel mundial encontramos varios países desarrollados que han puesto en funcionamiento un esquema SPG, promovidos por la OMC. Por ejemplo, el esquema europeo Everything But Arms $(E B A)^{5}$, en vigor desde marzo de 2001, prevé libre acceso a los mercados para todos los bienes provenientes de países PMA, con la excepción de armas y munición. Otro programa es el estadounidense African Growth and Opportunity Act (AGOA), sistema de preferencias específicas para los países de África Sub-Sahariana (ASS) puesto en marcha en el año 2000 (incluía textil). Japón y Canadá, con sistemas de SPG desde diciembre del año 2000, también han avanzado en la facilitación de la introducción de productos agrícolas y textiles provenientes de PMA.

\subsection{Los Sistemas Generalizados de Preferencias de la UE}

En 1971 la CEE firmó el primer SPG. Se empezó por la reducción de aranceles en cantidades limitadas de productos, lo que pronto se reemplazó por lo que fue conocido como modulación arancelaria: preferencias limitadas para cantidades ilimitadas. Se fue reduciendo la utilización de cuotas y techos y los productos que se consideraban no-sensibles pudieron entrar libremente en el mercado comunitario. Para los demás productos (que coinciden con los más sensibles debido a la situación del sector productivo europeo) se determinaron aranceles inferiores a los aranceles NMF (reducción del 15\% para los más sensibles y del 30 al $65 \%$ para los sensibles o semi-sensibles). Los productos protegidos por la PAC se excluyeron del esquema SPG.

En 2002 se modificaron las definiciones de los SPG. Los productos se clasificaron como sensibles o no sensibles, eliminando así categorías innecesarias. Se decidieron reducciones en los aranceles ad valorem y específicos. El sector textil y el de la pesca recibieron más facilidades comerciales.

\footnotetext{
${ }^{5}$ Esquema adoptado en febrero de 2001 (Regulación EC 416/2001). Hoy en día se benefician los 49 países PMA
} 
Valera, Eva. Los AAE entre la UE y África. La introducción de la reciprocidad y el caso de Ghana.

En 2008, las importaciones bajo preferencias SPG fueron de 68.600 millones de euros, como se puede ver en el siguiente cuadro. La provisión de preferencias arancelarias supuso una pérdida de ingresos aduaneros nominales para la UE de 3.284 millones de euros. También podemos observar que el mecanismo más utilizado es el SPG estándar, y que las concesiones arancelarias son mayores bajo el régimen Everything But Arms (EBA) que bajo $\mathrm{SPG}+{ }^{6}$.

\section{CUADRO 1}

Volúmenes comerciados bajo el SPG y su valor (2008)

$\begin{array}{cc}\text { Importaciones preferenciales } & \text { Pérdidas de ingresos aduaneros } \\ \text { bajo SPG }(\mathrm{M} €) & \text { nominales }(\mathrm{M} €)\end{array}$

$\begin{array}{lcc}\text { SPG Estándar } & 56.900 & 2.050 \\ \mathrm{SPG}^{+} & 5.800 & 577 \\ \mathrm{EBA} & 5.800 & 657 \\ \text { Total } & \mathbf{6 8 . 6 0 0} & \mathbf{3 . 2 8 4}\end{array}$

Fuente: Comisión Europea

Actualmente, los SGP europeos se dividen en tres modalidades:

a) EBA (Everything But Arms) con los PMA, que mejoró considerablemente el trato a los PMA que no formaban parte del grupo de ACP (por ejemplo, Bangladesh, Maldivas, Nepal y Yemen)

b) Acuerdos de Cotonú - AAE con los países ACP

c) Acuerdos Euro-Mediterráneos

Mientras que los SGP son sistemas que se proveen unilateralmente, los Acuerdos de Cotonú y los AAE son acuerdos legales entre dos partes, en los que existe un compromiso contractual para el acceso preferencial al mercado europeo para los productos provenientes de países ACP. Veamos el siguiente apartado.

\subsection{De Lomé a Cotonú}

En el año 1975 se firmaba el primer Acuerdo de Lomé entre la CEE y 46 países ACP. Este modelo, que tiene como antecedentes los esquemas de asociación de algunos países europeos con los Países y Territorios de Ultramar de 1957 y los Acuerdos de Yaundé I y II (firmados en 1963 y 1969 respectivamente), fue la principal herramienta de cooperación entre la entonces Comunidad Europea y los países ACP. Combinaba aspectos de ayuda (por ejemplo, a la industria minera y a la seguridad alimentaria), comerciales

\footnotetext{
6 El SGP+ representa preferencias adicionales para países o regiones especialmente vulnerables, ya sea por insularidad, por ser pequeños, de bajos ingresos o por no tener salida al mar. Suelen tener una estructura exportadora poco diversificada (cuando los 5 principales productos importados por la UE provenientes de ese país representan más del $75 \%$ de las importaciones totales de ese país). En el período 2009-2011 son 15 los países que se benefician de SGP+.
} 
Valera, Eva. Los AAE entre la UE y África. La introducción de la reciprocidad y el caso de Ghana.

(diversificación de la economía y promoción del sector privado, entre otros) y políticos (defensa de los derechos humanos y de los principios democráticos). Por lo que respecta al segundo aspecto, los sucesivos Acuerdos de Lomé (hubo cuatro) se basaron en un criterio de discriminación comercial positiva, por el cual se permitía la entrada libre de aranceles ad valorem provenientes de países ACP firmantes del acuerdo, que en el año 2000 ya eran más de 70 (incluyendo al $75 \%$ de los países PMA). Para los países PMA se garantizaba una entrada libre sin aranceles ni cuotas para casi todo el comercio (se exceptúan los productos 'sensibles', como varios productos de la PAC europea), mientras que para el resto de países ACP las preferencias se parecían mucho a las del SGP. La asistencia financiera se canalizaba a través de los Fondos Europeos de Desarrollo (FED). Entre 1959 y 2000 hubo ocho FED.

Los resultados conseguidos con Lomé fueron escasos. Por esta razón, la UE, bajo las presiones del GATT-OMC, decidió dar por agotado este marco y negociar uno nuevo, que además debía estar más acuerdo con las normas de la nueva OMC respecto a reciprocidad y no discriminación. No cabía la posibilidad de que el nuevo marco de relaciones estuviera sujeto a la excepción del art. XXIV, ya que no se pretendía la instauración de un acuerdo de integración regional.

Los países ACP intentaron prorrogar Lomé y el tratamiento no recíproco que recibían, pero a pesar de ello, el 23 de junio del año 2000 se firmó en Benín el Acuerdo de Cotonú, entre la entonces UE-15 y los 77 países ACP.

En el art.1 se puede leer: "la asociación debe centrarse en el objetivo de la reducción y eventual desaparición de la pobreza, que sea consistente con los objetivos de desarrollo sostenible y integración gradual de los países ACP en la economía mundial'.

La duración de Cotonú se estipuló en 20 años, pudiéndose revisar cada cinco años. Además de los temas del comercio, incluye un protocolo financiero por el cual se definen los fondos que los países ACP van a recibir del FED dedicados a las reformas fiscales, la construcción de infraestructuras y a la promoción de la inversión. En el Acuerdo se estableció el camino hacia una liberalización comercial recíproca y el avance en política de la competencia, derechos de propiedad intelectual, medidas sanitarias y fitosanitarias, entre otras, pero también se incluyen disposiciones para el refuerzo del diálogo en derechos humanos, democracia, buen gobierno, lucha contra la corrupción, prevención de riesgo de conflictos, procesos de paz y control de la inmigración ilegal. Aunque no se incluye el concepto de condicionalidad política, que se sustituye por el de diálogo político, existe la posibilidad por parte de la UE de suspender la ayuda en caso de incumplimiento de alguno de estos aspectos.

Para conseguir mejor los objetivos de desarrollo económico, diversificación e incremento del comercio y tener en cuenta las diferencias económicas regionales, se decidió que se firmarían distintos Acuerdos de Asociación Económica entre la UE y las distintas agrupaciones de países ACP. 
Valera, Eva. Los AAE entre la UE y África. La introducción de la reciprocidad y el caso de Ghana.

En un discurso en la London School of Economics de febrero de 2005, el Comisario Europeo de comercio, Peter Mandelson, decía que "Los $A A E \ldots$ no deben ser vistos como acuerdos comerciales en el sentido convencional en el que ambas partes buscan ventajas mutuas... El objetivo de los $A A E$ es la promoción de la integración regional y del desarrollo económico".

Debe quedar claro que estos acuerdos están insertos dentro del Acuerdo de Cotonú. Para entender mejor cómo funcionan nos vamos a centrar en los acuerdos que afectan a África Sub-Sahariana, concretamente en el caso de África Occidental a través del AAE interino que se va a firmar entre Ghana y la UE.

\subsection{Acuerdos de Asociación Económica UE - África}

En el mencionado art. XXIV del GATT se establecía la posibilidad de discriminación en el caso en el que se dé una integración regional de tipo unión aduanera (UA) o acuerdo de libre comercio (ALC). Como se ha mencionado, el acuerdo de Cotonú no contempla la posibilidad de implantar ninguna de las dos formas de integración con las distintas regiones ACP de manera estricta, por lo que se hace necesario un nuevo marco de relaciones en el que, si bien los países PMA siguen exentos de algunas obligaciones del GATT, se pretende disminuir en cierta medida el grado de discriminación frente a terceros países ${ }^{7}$ e introducir la reciprocidad. De ahí nacen los AAE, que no se definen en sentido estricto como ALC a pesar de compartir muchas de sus características, sino como Acuerdos Comerciales Regionales.

Las negociaciones se hacen con grupos de países ACP. En el caso de las negociaciones con África, se establecen como interlocutores para la UE cinco grupos regionales de países:

- grupo 1- Comunidad Económica y Monetaria de África Central (CEMAC), formado por Camerún, Rep. Centroafricana, Chad, Congo - Brazzaville, Rep. Democrática del Congo, Guinea Ecuatorial y Gabón, a los que se suma São Tomé e Príncipe; la ECA (Kenya, Uganda, Tanzania, Rwanda y Burundi),

- grupo 2- Comunidad Económica de los Estados de África del Oeste (ECOWAS-CEDEAO), formada por Benin, Burkina Faso, Cape Verde, Costa de Marfil, Gambia, Ghana, Guinea, Guinea-Bissau, Liberia, Mali, Níger, Nigeria, Senegal, Sierra Leone, Togo, a los que se suma Mauritania;

- grupo 3- Grupo del Este y Sureste (ESA), formada por Comoros, Djibouti, Eritrea, Etiopía, Malawi, Mauricio, Madagascar, Seychelles, Sudán, Zambia y Zimbabwe;

- grupo 4- Comunidad de Desarrollo del África Austral (SADC), formada por Angola, Botswana, Lesotho, Mozambique, Namibia, Sudáfrica y Swazilandia;

- grupo 5- Comunidad de Países del Este de África (CEA), formada por Kenia, Uganda, Tanzania, Rwuanda y Burundi.

\footnotetext{
${ }^{7}$ En el seno de la OMC se está presionando para eliminar cualquier tipo de excepción a los principios de no discriminación y de reciprocidad (excepto el art. XXIV), pero hoy en día sigue vigente en los SGP y en el trato diferenciado a los PMA.
} 
Valera, Eva. Los AAE entre la UE y África. La introducción de la reciprocidad y el caso de Ghana.

El modelo de cooperación se basa en los principios de asociación, el diálogo, los derechos y deberes contractuales y la previsibilidad de la ayuda. Respecto a la asociación, la UE se compromete a eliminar todas las barreras comerciales, mientras que los países ACP deben implementar políticas para la mejora de la oferta y la reducción de los costes de transacción.

Principios en los que se basa la cooperación:

- Igualdad entre las partes y apropiación de las estrategias por parte de las instituciones locales;

- Participación (sociedad civil, sector privados, autoridades locales);

- Diálogo y acuerdos mutuos (por ejemplo, el respeto a los derechos humanos);

- Diferenciación (según el nivel de desarrollo de la contraparte y su estrategia de desarrollo a largo plazo) y regionalización.

Los AAE se traducen en políticas económicas y comerciales por un lado y de ayuda por el otro. Respecto al primer punto, en este acuerdo se establece que las preferencias arancelarias no recíprocas mantenidas desde los acuerdos de Lomé-IV se mantienen hasta el 31 de diciembre de 2007, momento en el cual deben ser reemplazadas por los acuerdos AAE $u$ otros acuerdos comerciales. Los $A A E$ serán compatibles con las reglas que rigen la $\mathrm{OMC}^{8}$, y se firmarán con los países individualmente o con las regiones y grupos de países que estén en proceso de integración. Los países PMA seguirán manteniendo las preferencias no recíprocas. En lo que se refiere a la ayuda, se traducirá en medidas de cooperación financiera y técnica.

Objetivos prioritarios:

- Desarrollo económico (a través, entre otros aspectos, de la apertura comercial);

- Desarrollo social y humano;

- Integración y cooperación regionales.

En lo que se refiere a la liberalización o apertura comercial, si tomamos como referencia el art. XXIV de la OMC, se estipula que se debe liberalizar "casi todo el comercio". La ambigüedad del casi queda patente en la dificultad con la que se están llevando a cabo las negociaciones. Hay otros aspectos en los que hay controversia, como el que debe cumplir con el párrafo $5 \mathrm{c}$ del mencionado artículo, en el que se menciona que los procesos de liberalización deben llevarse a cabo en "un periodo de tiempo razonable". La letra no escrita estipula que será alrededor de 10 años, aunque en el acuerdo de libre comercio entre Suráfrica y la UE el período se alargó a los 12 años.

Las negociaciones de los AAE están siendo difíciles también por otros motivos. La crisis actual ha afectado mucho a algunos países en desarrollo, principalmente a través de la disminución de la demanda internacional de sus

\footnotetext{
${ }^{8}$ Art. 36(1): "En vista de los objetivos y de los principios determinados anteriormente, las Partes acuerdan concluir nuevos acuerdos comerciales compatibles con la Organización Mundial del Comercio (OMC), eliminando progresivamente las barreras al comercio entre ellas y fortaleciendo la cooperación en todas las áreas relevantes para el comercio" (traducción de la autora)
} 
Valera, Eva. Los AAE entre la UE y África. La introducción de la reciprocidad y el caso de Ghana.

exportaciones, la caída en los precios de algunas materias primas y por la mayor dificultad de acceso a crédito internacional, así como una caída en la IED. También ha afectado a los países desarrollados, con lo que las negociaciones están yendo a un ritmo bastante lento. Los PED, que presionan en las mesas de negociaciones de la OMC con una sola voz, reclaman reformas del mercado agrario internacional y la facilitación del comercio (reformas destinadas a homogeneizar los trámites administrativos de entrada a los mercados de las economías desarrolladas y de las emergentes). No aceptan la existencia de una PAC que distorsiona el mercado agrícola, y por ello las negociaciones de los acuerdos bilaterales con la UE no avanzan tan rápido como a esta última le gustaría. Durante este proceso de negociación, los PMA pueden seguir comerciando bajo el régimen EBA, mientras que los otros países mantienen las preferencias de los SGP.

\subsection{EI AAE entre la UE y Ghana}

Ghana, ex colonia británica independizada en 1957, es un país rico en oro, madera, diamantes, bauxita y cacao (de este último es el segundo productor mundial tan solo por detrás de la vecina Costa de Marfil). Sin embargo, sigue siendo un país pobre, con una renta per cápita que en 2007 se situó en los 1653,26 dólares (aunque no llega a ser considerado PMA al no tener una renta inferior a los 800 dólares per cápita). La agricultura supuso en 2008 el 37,7\% del PIB (y el $56 \%$ de la población ocupada), mientras que la industria representó el 25,3\% (15\% de ocupación) y el sector servicios el 37,5\% restante del PIB (29\% de la población ocupada) (CIA Worldfactbook).

Este país forma parte del grupo de países de África Occidental. Las negociaciones entre la UE y este grupo comenzaron oficialmente el 6 de octubre de 2003, e incluyen a dos grupos de países del oeste de África: la UEMOA (Unión Económica y Monetaria del Oeste de África, que comprende Benín, Burkina Faso, Costa de Marfil, Mali, Níger, Senegal, Togo y GuineaBissau, que cuentan con una moneda común - CFA-, con un tipo de cambio fijo respecto al euro) y el resto de países de la CEDEAO.

Es una zona importante para la UE, ya que, según datos oficiales, el comercio con esta región significa el $40 \%$ de todas las importaciones a la UE desde los países ACP. Para África Occidental, la UE es el destino de alrededor del $32 \%$ de sus exportaciones. Los principales productos exportados por la región africana son minerales (principalmente petróleo proveniente de Nigeria, así como gas, hierro, aluminio y oro), productos agrícolas (cacao, fruta fresca), pescado y crustáceos y productos forestales (madera y caucho). La UE exporta petróleo, bienes de capital (eléctricos, vehículos de transporte), medicinas y productos lácteos. En 2008, los intercambios comerciales entre ambas partes fueron de 43.600 millones de euros. De todas las regiones que negocian AAE, África Occidental es la mayor en términos comerciales.

A finales de 2007, fecha en la que se terminaba el plazo para la firma de los AAE regionales, todavía no había acuerdo entre África Occidental y la UE. Los principales escollos se encontraban en las tasas a la exportación, los impuestos regionales y la cláusula NMF. Otro aspecto importante de 
Valera, Eva. Los AAE entre la UE y África. La introducción de la reciprocidad y el caso de Ghana.

divergencia es el de las normas de origen. Por ahora se sigue utilizando la regulación 1528/2007 que aparece en el Acuerdo de Cotonú hasta que haya un nuevo acuerdo.

La falta de un marco regulatorio del comercio afectaba de manera importante a Ghana, ya que perdería las preferencias de entrada al mercado europeo y debería pagar mayores impuestos a la importación europea en el marco de los SGP a partir del 1 de enero de 2008 (situación también de otros 36 países ACP que no son PMA, como Kenia y Mauricio). Para evitar esta situación, Ghana debía decidir entre varias opciones:

- 1a opción: Pedir nuevas dispensas a la reciprocidad:

La UE y los estados ACP podrían pedir una nueva dispensa, o excepción, para continuar operando bajo un sistema de preferencias para el país ACP. No se llevó a cabo por el coste que esta petición suponía para la UE, por las presumibles protestas por parte de países no ACP que pedirían reducciones arancelarias de entrada al mercado europeo como compensación y por la casi segura negativa de la OMC ante tal petición.

- 2a opción: Sistema General de Preferencias (SGP):

Este sistema permitiría a Ghana exportar azúcar con aranceles bajos, pero este sistema funciona para todos los PED, y algunos de estos son competidores directos de las exportaciones ghanesas.

- $3^{a}$ opción: SGP+:

Este sistema podría ser beneficioso para Ghana, pero el problema está en las 27 condiciones que impone la ONU para que un país sea aceptado en este esquema. Ghana cumple con 25 de ellas, pero aunque avanzara en el cumplimiento de las restantes, nadie le asegura una pronta incorporación al sistema, ya que el procedimiento administrativo puede tardar años en completarse.

- 4a opción: EBA:

Ghana no es un PMA, así que este sistema de preferencias queda descartado.

- 5a opción: AAE provisional:

Finalmente esta es la opción que se ha llevado a cabo, aunque solo sirve para ganar tiempo hasta que se firmen los acuerdos regionales. Así se asegura que el comercio entre Ghana y la UE seguirá igual que antes ${ }^{9}$.

EI AAE UE - Ghana se basa en:

1) Comercio de bienes:

a) Acceso libre sin aranceles en el mercado de la UE para todas las importaciones provenientes de Ghana desde el 1 de Enero de 2008, con períodos de transición para el arroz y el azúcar,

\footnotetext{
${ }^{9}$ La ministra de Comercio e Industria de Ghana, Hanna Tetteh, declaró en enero de 2011 que "Ghana, Nigeria y Costa de Marfil son países en desarrollo y no PMA, así que no están en condiciones de beneficiarse de los mismos acuerdos que los países de la CEDEAO que son PMA y que se pueden beneficiar de los acuerdos EBA, así que debemos actuar de distinta manera. Costa de Marfil ha firmado el AAE interino, Nigeria no lo hará y se acoge al SPG+. No seremos competitivos si nos decidimos por el SGP+ así que debemos asegurarnos que este año podamos finalizar los acuerdos en relación a nuestro AAE interino dada la falta de avance en la CEDEAO" (traducción de la autora)
} 
Valera, Eva. Los AAE entre la UE y África. La introducción de la reciprocidad y el caso de Ghana.

b) Apertura asimétrica y gradual del mercado de Ghana a los productos de la UE, teniendo en cuenta las diferencias de desarrollo entre ellos,

c) Defensa del comercio con medidas de salvaguardia bilaterales que permiten a ambas partes la reintroducción de aranceles o cuotas si las importaciones de la otra parte perturban o amenazan de perturbar su economía,

d) Un capítulo sobre las barreras técnicas al comercio, así como las sanitarias y fitosanitarias para ayudar a los exportadores de África Occidental a cumplir con los estándares europeos,

e) Facilitación del comercio mediante medidas que mejoren la eficiencia de las aduanas y la mayor cooperación entre administraciones.

2) Bienes liberalizados en el AAE:

Todas las importaciones procedentes de Ghana entran libres de cuotas y aranceles en el mercado europeo desde el 1 de junio de 2008, con excepción del arroz (a partir de 2010) y del azúcar (a partir de 2015). Ghana deberá liberalizar el $80 \%$ de sus importaciones procedentes de la UE (lo que representa el $81 \%$ de las líneas arancelarias). El período de transición se estipula en 15 años. Los bienes europeos liberalizados son, principalmente, maquinaria industrial (bombas, generadores, turbinas, etc.), algunos vehículos (barcos, aviones y coches) y algunos productos químicos.

3) Bienes no liberalizados en el AAE:

Ghana excluye algunos productos de la lista de productos libres de aranceles, tanto agrícolas como no-agrícolas, por considerarlos productos sensibles para su economía. Entre otros, se excluyen la carne de pollo y de otros animales, tomates, cebollas, azúcar, tabaco, cerveza y prendas de vestir. También se excluye el trigo, el pescado congelado y los plásticos industriales.

4) Reglas de Origen:

Todavía no hay acuerdo. Hasta entonces, Ghana sigue bajo el paraguas general de reglas de origen (Regulación del Consejo 1528/2007).

5) Cooperación al desarrollo:

Las principales áreas son el refuerzo y mejora de la capacidad de los sectores productivos, la cooperación en ajuste fiscal, la mejora del entorno de negocios y la implementación de las reglas comerciales en los acuerdos

\section{ANÁLISIS DEL AAE GHANA - UE y CRÍTICAS AL MISMO}

Cabe plantearse cuáles son las potenciales ganancias y pérdidas de este tipo de acuerdos si tenemos en cuenta que tratamos de economías con estructuras marcadamente distintas, así como niveles de desarrollo bien dispares. Los países PMA, que podrían decidir comerciar bajo el esquema EBA, aceptan estos acuerdos por el componente de ayuda al desarrollo (principalmente financiera) que contienen, dado que el EBA es puramente comercial. Para los no-PMA, como es el caso de Ghana, es la única salida si quieren mantener un nivel de preferencias mínimo.

Siempre tendremos en cuenta el contexto en el cual se están llevando a cabo las negociaciones, que es el de la Ronda de Doha de la OMC. En esta Ronda 
Valera, Eva. Los AAE entre la UE y África. La introducción de la reciprocidad y el caso de Ghana.

se negocia la liberalización agrícola (incluidos los protocolos como los del azúcar o de la carne). Analicemos primero el comercio entre la UE y Ghana.

\subsection{Análisis del comercio}

Como se puede observar en los siguientes gráficos, la UE ha mantenido e incluso incrementado su cuota como destino de las exportaciones de Ghana (de un 53\% en 1985 a un $63 \%$ en 1995 y un $53 \%$ en 2006 ), pero sin embargo ha ido disminuyendo su importancia como proveedor de importaciones a ese país (52\% en 1985, 45\% en 1995 y $35 \%$ en 2006$)$.

\section{GRÁFICO 1}

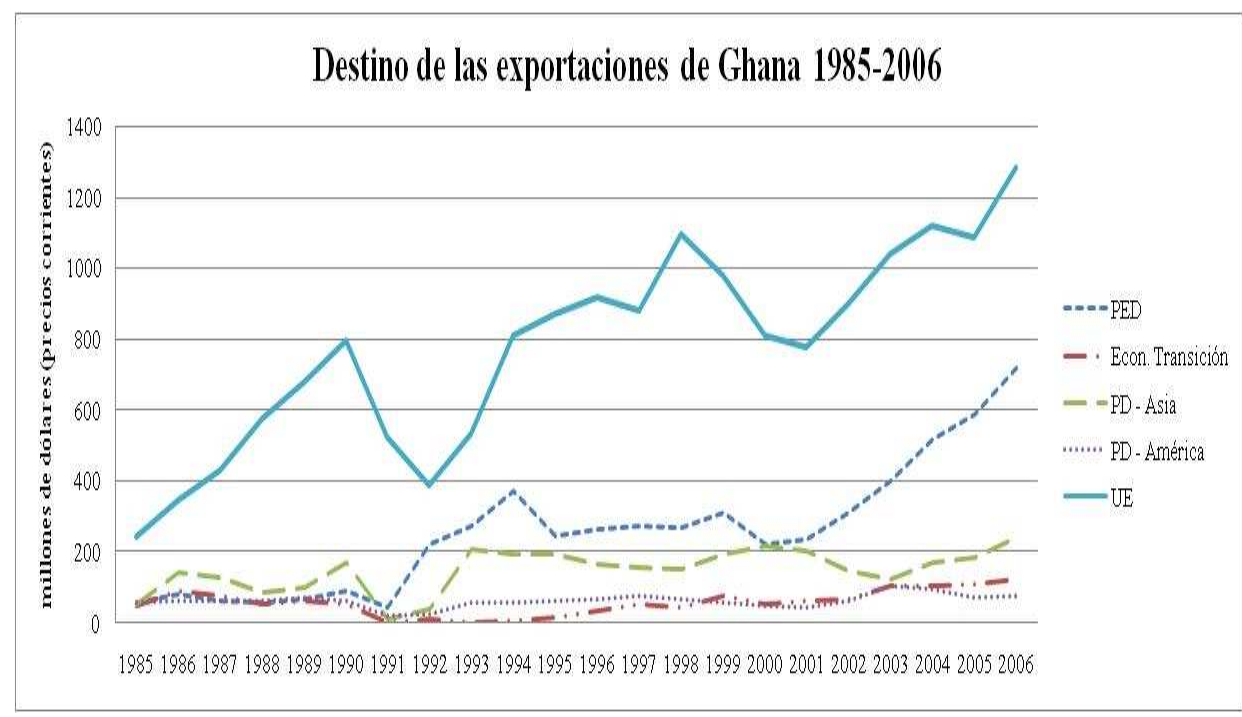

Fuente: elaboración propia a partir de la base de datos de la UNCTAD, última visita mayo de 2010.

\section{GRÁFICO 2}

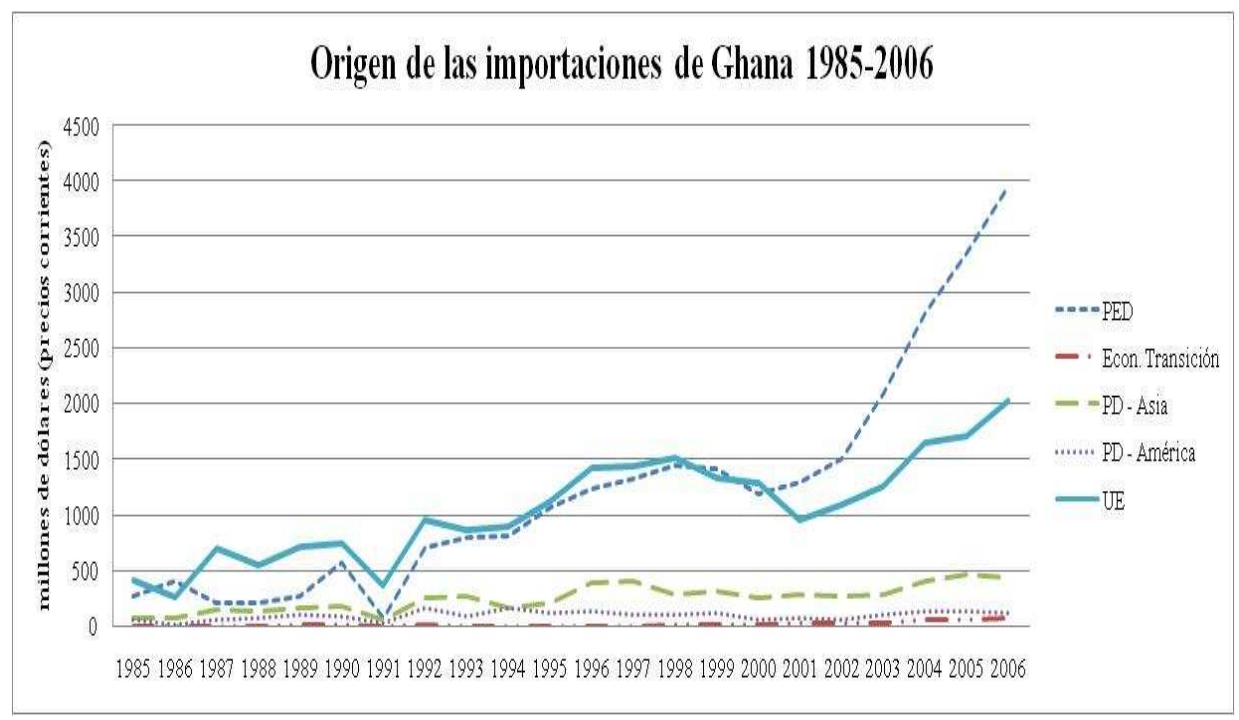

Fuente: elaboración propia a partir de la base de datos de la UNCTAD, última visita mayo de 2010.

Vemos que los países en desarrollo están incrementado su peso como destino de las exportaciones ghanesas, pero siguen estando en segundo lugar. Sin embargo, en el caso de las importaciones, los PED han pasado por delante de 
Valera, Eva. Los AAE entre la UE y África. La introducción de la reciprocidad y el caso de Ghana.

la UE (se incluye a China en este apartado, pero también son importantes las importaciones provenientes de Suráfrica). Observamos que este fenómeno se ha ido acrecentando a partir de los años 2000. Por tanto, la UE está perdiendo claramente cuota de mercado frente a las nuevas potencias mundiales emergentes.

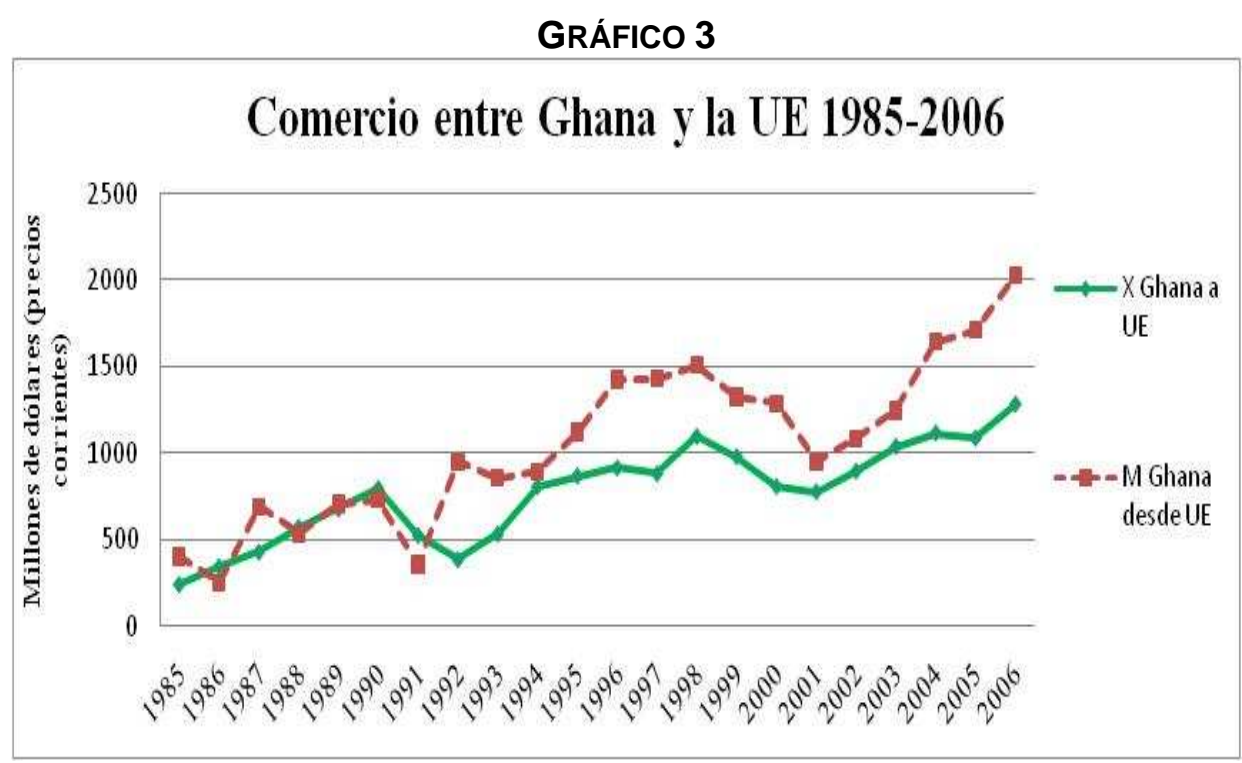

Fuente: elaboración propia a partir de los datos de la UNCTAD, última visita mayo de 2010.

Veamos ahora con más detalle la evolución del comercio entre la UE y Ghana. Tan solo en algunos años entre 1986 y 1991, las exportaciones de Ghana a los países que hoy conforman la UE superaron a las importaciones procedentes de esos países. Desde entonces, las exportaciones europeas hacia Ghana han sido mayores y en aumento, superando con creces a las importaciones. Así, en 1992 las exportaciones de Ghana hacia la UE eran de 385 millones de dólares y las importaciones rondaban los 952 millones, mientras que en 2006 las exportaciones se situaban en 1283 millones, las importaciones llegaban a los casi 2.024 millones de dólares, lo que supone un saldo negativo para Ghana de más de 740 millones.

Cabe esperar, no obstante, una reversión de este fenómeno a partir de la comercialización del petróleo de Ghana, que se prevé que empiece a finales de 2010.

\subsubsection{Productos comerciados entre Ghana y la UE}

Para mejor analizar los efectos de la liberalización comercial es necesario conocer los principales productos importados y exportados por Ghana con su socio europeo. Los datos de comercio facilitados por las fuentes oficiales de la UE nos indican que la maquinaria y los vehículos (distintos a trenes y tranvías) son los productos más importados por Ghana, seguidos de los productos químicos y del petróleo. Así mismo podemos observar que la alimentación (principalmente cereales) aparece en quinto lugar. 
Valera, Eva. Los AAE entre la UE y África. La introducción de la reciprocidad y el caso de Ghana.

\section{GRÁFICO 4}

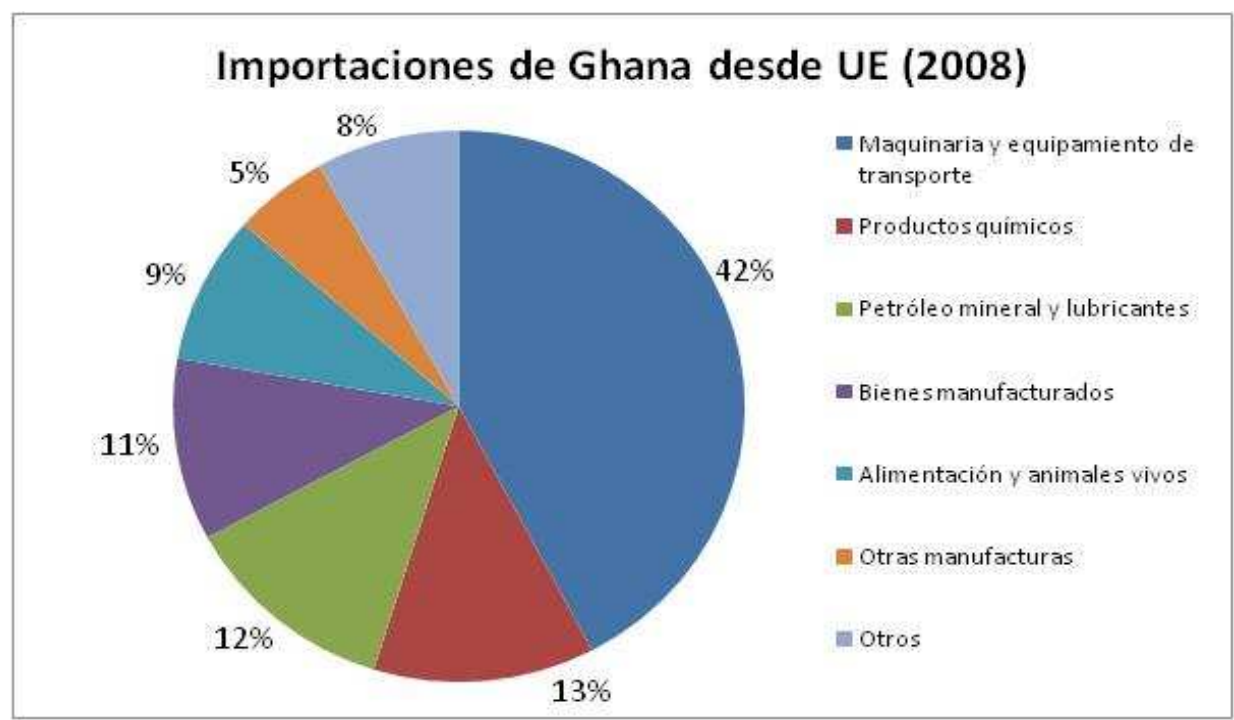

Fuente: Departamento de Comercio de la UE, última visita el 8 de junio de 2010.

La mayor parte de estos productos no se producen en Ghana, a excepción de los alimentos y de algunos productos de industria química.

En el caso de las exportaciones de Ghana hacia la UE, los productos de alimentación (entre ellos el cacao) son más del $80 \%$ de los principales 10 productos exportados (y representan el 1,4\% del total de importaciones de alimentación y animales vivos de la UE). Les sigue el oro (materia prima que, como el cacao, no se producen en grandes cantidades en Europa) y los bienes manufacturados (especialmente los plásticos). Estos bienes de poco valor agregado ya entraban libres de aranceles antes de la entrada en vigor del AAE, así que no se espera un cambio en la estructura exportadora ni en los volúmenes comercializados.

\section{GRÁFICO 5}

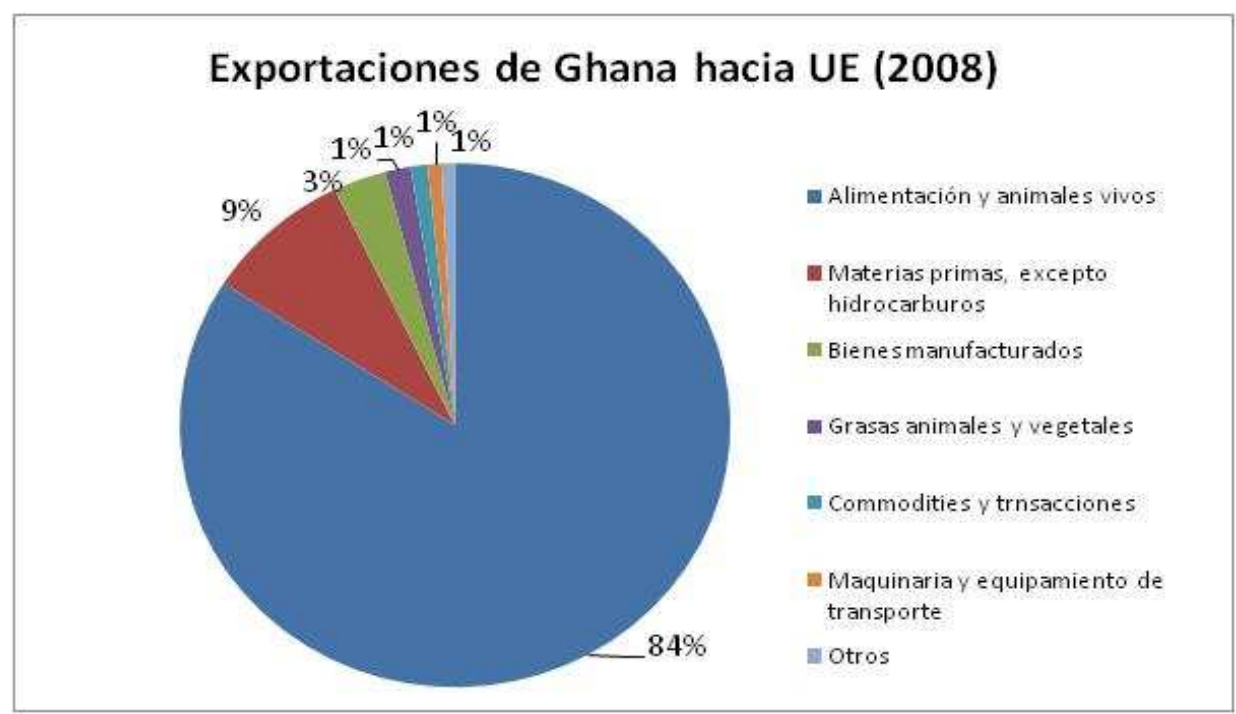

Fuente: Departamento de Comercio de la UE, última visita el 8 de junio de 2010. 
Valera, Eva. Los AAE entre la UE y África. La introducción de la reciprocidad y el caso de Ghana.

\subsubsection{Aranceles}

Los siguientes datos son los más recientes respecto a los aranceles, y son los recogidos por la OMC.

\section{CuAdro 2}

\begin{tabular}{|c|c|c|c|c|c|c|}
\hline & \multicolumn{2}{|c|}{ Total } & \multicolumn{2}{|c|}{ Agrícolas } & \multicolumn{2}{|c|}{ No-agrícolas } \\
\hline & UE & Ghana & UE & Ghana & UE & Ghana \\
\hline arancel medio (NMF) (2008) & $5,6 \%$ & $13,0 \%$ & $16,0 \%$ & $17,4 \%$ & $4,0 \%$ & $12,3 \%$ \\
\hline $\begin{array}{l}\text { importaciones totales (2007) (miles de } \\
\text { millones de dólares) }\end{array}$ & 1755,1 & 5,5 & 71,6 & 0,7 & 1683,4 & 4,8 \\
\hline arancel medio ponderado & $2,7 \%$ & $8,5 \%$ & $4,6 \%$ & $16,4 \%$ & $2,7 \%$ & $7,5 \%$ \\
\hline importaciones libre de aranceles & & & $29,6 \%$ & $2,8 \%$ & $26,2 \%$ & $13,3 \%$ \\
\hline
\end{tabular}

\section{Elaboración propia}

Notas: el arancel medio ponderado se obtiene a partir de las medias de los aranceles NMF para cada categoría de 6 dígitos ponderada por los flujos de importación de cada una de esas categorías. Datos UE de 2007, Ghana de 2006. Datos importaciones totales UE 2007, Ghana 2006.

Fuente de los datos: Tariff profiles 2009, OMC

Vemos como el arancel medio ponderado es menor que el arancel medio NMF tanto en la UE como en Ghana, y que los aranceles para los productos agrícolas siguen siendo mayores que los aranceles para los productos no agrícolas. Esto es una muestra de la continua protección del sector agrícola, defendido de manera severa por la UE en el seno de las negociaciones en la Ronda de Doha sobre la liberalización del comercio de productos agrícolas.

Podríamos calcular los ingresos que se dejarían de obtener si se diera una total liberalización del comercio. Mientras que para la UE esta es una 'pérdida' de 47 mil millones de dólares, para Ghana serían 467,75 millones de ingresos por aranceles menos. Esta 'pérdida' representaría menos de un 0,0001\% del PIB europeo, mientras que lo que representaría para Ghana sería de cerca del $2 \%{ }^{10}$. Además, en el caso de los productos agrícolas, las 'pérdidas' para la UE se reducen a unos 3 mil millones, mientras que para Ghana son casi 115 millones menos, lo que representa el $25 \%$ de las 'pérdidas'. En cifras absolutas las cantidades son muy distintas y las pérdidas mayores para la UE, pero hay que tener en cuenta el tamaño de las economías de las que estamos hablando.

El análisis que acabamos de hacer es para el comercio con todos los países en su conjunto, pero si nos centramos un momento en el comercio entre la UE y Ghana (ver Anexo 3), vemos que para este último país no queda demasiado margen de reducción de los aranceles a los que se enfrenta cuando entra al mercado europeo, ya que el $97,1 \%$ de los productos agrícolas ghaneses que entran en este mercado lo hacen ya libres de aranceles, y el porcentaje sube al

${ }^{10}$ PIB de la UE en 2008 de 14,45 billones de dólares, y de Ghana de 31.130 millones de dólares). 
Valera, Eva. Los AAE entre la UE y África. La introducción de la reciprocidad y el caso de Ghana.

$100 \%$ en el caso de productos no agrícolas. Además, esta liberalización se da en una larga lista de líneas arancelarias, como nos indica la diversificación de las exportaciones bilaterales, por lo que ese margen es mucho más reducido que en el caso, por ejemplo, del comercio bilateral de productos agrícolas con Japón, Malasia y EEUU, o del no-agrícola con Hong Kong y EEUU (estos países siguen a Europa en orden de importancia en términos de millones de dólares comercializados).

Recordemos que hay una serie de sectores que se excluyen de la liberalización, por lo que mantendrán los aranceles. Si miramos el Anexo 4, vemos que en el año 2006 los aranceles que imponía Ghana a las importaciones eran el 19,6\% para la carne de pollo, 18,9\% para los tomates y las cebollas, 19,9\% para la cerveza y el tabaco, 11,3 para el azúcar, 20\% para las prendas de vestir, $17,8 \%$ para el trigo y $11,1 \%$ para el pescado congelado (sin datos para los plásticos industriales), todos ellos productos que mantendrán, por ahora, las tasas de protección actuales.

Por el contrario, también vemos en el anexo 4 que hay productos que Ghana importa en gran medida y que no superaban en 2006 más del $70 \%$ de liberalización, por lo cual la entrada libre de aranceles de este tipo de productos, como son los minerales e hidrocarburos ${ }^{11}$, productos químicos, madera y papel, maquinaria eléctrica y equipamiento de transporte pueden significar las mayores pérdidas de ingresos por aranceles, ya no solo debido a la eliminación de los aranceles de los productos provenientes de Europa, sino a las menores importaciones provenientes de otros países, que, a pesar de ser más eficientes ${ }^{12}$, se ven relegadas a favor de los productos europeos.

\subsection{Efectos positivos}

Todavía es pronto para analizar en profundidad los efectos que tienen los AAE sobre la economía de los países ACP, en este caso, de Ghana. Podemos predecir que algunos posibles efectos positivos son el reforzamiento y reorganización eficiente de los grupos regionales existentes ${ }^{13}$; la mejora de la productividad y la competitividad; la atracción de inversiones exteriores; una mejor inserción en la economía mundial, y el crecimiento económico en las economías más desfavorecidas. Pero los períodos de transición hacen que el análisis sea complicado.

Sí podemos ver que, con el AAE, a Ghana le sale más barato comprar bienes intermedios y de capital, como por ejemplo turbinas, generadores eléctricos industriales, aviones y algunos productos químicos. Ghana no produce estos bienes así que esto puede reducir los costes y mejorar la calidad de los bienes de consumo y de los inputs que utilicen las industrias, así como la reducción

\footnotetext{
${ }^{11}$ Aunque a partir de 2011 Ghana se va a convertir en exportadora neta de petróleo cuando empiece a comercializar los hidrocarburos de los yacimientos de Jubilee.

${ }^{12}$ Lo cual se puede inferir del hecho de que, a iguales aranceles (es decir, antes de la puesta en vigor del APE) se estuvieran importando los productos de esos países no europeos.

${ }^{13}$ Solución al llamado spaguetti bowl, término que se refiere al solapamiento de acuerdos regionales de integración en el caso concreto de África; para ello, deberían tenerse en cuenta las necesidades concretas de los africanos y las características de los países y regiones interlocutoras, y no seguir criterios externos homogeneizadores de un continente tan diverso.
} 
Valera, Eva. Los AAE entre la UE y África. La introducción de la reciprocidad y el caso de Ghana.

del déficit en la Balanza Comercial, ya que "los importadores - compradores finales- [...] a) aumentan su utilidad en el consumo y/o el propio consumo, con lo que aumenta su renta real; b) aumentan sus beneficios presentes o futuros, reduciendo costes y haciendo más competitivos los productos (bienes intermedios y de capital)" (Oyarzun, 1995). Además, varios productos agrícolas se excluyen del acuerdo de liberalización comercial para evitar la competencia de los productos agrícolas europeos subvencionados en el mercado ghanés. Parece ser que está previsto revisar, sin embargo, los protocolos agrícolas, aunque no queda muy claro en qué medida: "Se está de acuerdo en la necesidad de revisar [los protocolos] en el contexto de los nuevos acuerdos comerciales, en particular en lo que se refiere a la compatibilidad con las normas de la OMC, con vistas a salvaguardar los beneficios derivados de ellos, teniendo en cuenta el estatus legal especial del Protocolo del Azúcar" (art. 36(4) del Acuerdo de Cotonú). Por su parte, todas las exportaciones de Ghana entran libres de aranceles al mercado europeo (con la excepción del azúcar hasta 2015).

En lo que se refiere a la atracción de inversiones, éstas solo resultarán beneficiosas para Ghana si se dirigen a sectores que permitan diversificar la economía, mejorar la industria manufacturera y los servicios (los financieros, por ejemplo, se están desarrollando mucho con miras a la comercialización del petróleo). Sin embargo es necesario introducir criterios de calidad de las inversiones para que no responda tan solo a la búsqueda de costes laborales más bajos y mayor rendimiento de las inversiones en la industria extractiva y de bienes no procesados.

En definitiva, se espera mayor ayuda técnica y financiera, cooperación y creación de capacidad productiva.

\subsection{Efectos negativos}

El comercio global y libre no tiene por qué significar desarrollo económico de los países más pobres del planeta. Asimismo, las recetas de recorte del sector público y la liberalización de los sectores financiero y comercial que, entre otros aspectos, se recogían en el "Consenso de Washington", han ido frenando los movimientos panafricanistas y de integración regional en África. Los AAE pretenden un regionalismo teórico, entendido como second best o regionalismo abierto como paso intermedio hacia la desregulación y apertura total del conjunto de economías "asociadas" (Bidaurratzaga et al, 2006). Por tanto, los AAE pueden seguir impidiendo un regionalismo africano real, lo que supondría oponerse al camino marcado por los propios países africanos.

Por otro lado, Karingi et al, en su estudio Economic and welfare impacts of the EU-Africa Economic Partnership Agreements, de 2005, hacen un análisis pormenorizado sobre los efectos de los AAE en las economías africanas ${ }^{14}$. Su principal conclusión es que estos acuerdos pueden ser muy perjudiciales para los países de África, ya que pueden comportar pérdidas de ingresos, costes de

\footnotetext{
${ }^{14}$ A través de un modelo GTAP (Global Trade Analysis Project), que es un modelo de equilibrio general (CGE), consiguen hacer una aproximación cuantitativa, multi-país y teniendo en cuenta los vínculos intersectoriales, de los efectos del AAE sobre los países africanos.
} 
Valera, Eva. Los AAE entre la UE y África. La introducción de la reciprocidad y el caso de Ghana.

ajuste por la desindustrialización y un freno a la integración regional. Citando a los autores, "[El] resultado nos indica que, a menos que los AAE estén dispuestos a incluir hasta los sectores que se perciben más sensibles en la UE, parece que las economías africanas no se van a beneficiar" (pág. 20). Karingi et al creen que es necesario un tiempo de ajuste que permita a las economías africanas construir sus propios programas de desarrollo a nivel regional, es decir, aumentar el tamaño para así poder incrementar las capacidades productivas y conseguir la diversificación de la economía, aunque apuntan a que la mejor vía para cumplir con los requisitos de reciprocidad de la OMC sería la creación de un Área de Libre Comercio en la cual no existieran, por ejemplo, barreras no arancelarias al comercio. Como esta solución es poco probable que se dé, defienden la integración regional sin plena implementación de las medidas de reciprocidad, al menos al principio.

\subsubsection{Sectores más perjudicados}

En el caso de un sistema de reciprocidad total, sin una previa integración regional, los sectores más perjudicados no serían los agrícolas, ya que se estima que la producción de estos sectores incluso podría incrementarse, como muestran Karingi et al. (2005). Según estos autores, el sector más perjudicado sería el de la industria pesada y la industria de baja tecnología, que son los sectores que primero se desarrollan en un clásico esquema de industrialización. Este resultado ahondaría en la estructura primario exportadora de muchos países africanos, incluida Ghana, y con la firma del AAE provisional (sin esperar a una firma conjunta de la región occidental africana) se está frenando la integración regional. Para conseguir una diversificación productiva, que aparece entre los objetivos de los Acuerdos de Cotonú $^{15}$, se debería fomentar realmente la integración regional para así conseguir vínculos intersectoriales y aumento de capacidad productiva. Sin ella, es posible que se destruya la industria incipiente.

El textil y la confección también estarían siendo perjudicados por la reciprocidad con la UE sin previa integración (Karingi et al., 2005).

\subsubsection{Empleo y otros factores de producción (tierra y capital)}

Mientras que es posible un incremento en el empleo de baja calificación, el que se emplea en los sectores del algodón, agricultura, recursos naturales y, posiblemente, procesamiento de alimentos, los AAE pueden tener un efecto negativo sobre el trabajo cualificado, ya que la industria resultaría perjudicada, principalmente la industria pesada (Karingi et al., 2005).

\footnotetext{
${ }^{15}$ Art. 28 del Acuerdo de Cotonou: "[...] el apoyo a la cooperación debe buscar a) el fomento de la integración gradual de los países ACP en la economía mundial, b) acelerar la cooperación económica y el desarrollo tanto entre como dentro de la regiones de los Estados ACP, [...] d) acelerar la diversificación de las economías de los Estados ACP, y coordinar y armonizar las políticas de cooperación regional y sub-regionaf'. El art. 29 trata sobre la integración regional económica en detalle.
} 
Valera, Eva. Los AAE entre la UE y África. La introducción de la reciprocidad y el caso de Ghana.

\subsubsection{Pérdida de bienestar}

En Karingi et al. se determina que la pérdida de bienestar en un sistema de reciprocidad será alta, principalmente vía pérdida en los términos de intercambio y por el déficit comercial que pueda comportar el probable crecimiento de las importaciones provenientes de los países europeos. Hay que tener en cuenta que mayores importaciones significan mayores salidas de divisas para pagarlas, lo que puede provocar desajustes macroeconómicos por la reducción en las reservas de moneda extranjera.

También están los escasos beneficios derivados de la atracción de inversiones en condiciones muy beneficiosas para el capital extranjero, así como la vulnerabilidad de determinados sectores ante la competencia europea (desindustrialización y desempleo).

\subsubsection{Pérdida de ingresos fiscales}

Una de las mayores pérdidas que se darán con la plena entrada en vigor del AAE es la reducción de los ingresos fiscales de los gobiernos de los países $\mathrm{ACP}$, principalmente vía pérdida de ingresos aduaneros. Para el conjunto de países $A C P$, se prevé que se pierdan entre el 40 y el $60 \%$ de la recaudación provenientes de los ingresos aduaneros de las importaciones de origen europeo (IDS, 2005), y no vendrán solo de los menores aranceles impuestos a las importaciones europeas, sino que se le deberá sumar la reducción arancelaria entre los distintos países que conformen la región firmante del acuerdo. Como ya hemos analizado anteriormente, Ghana perderá importantes ingresos arancelarios con la liberalización de varias de sus importaciones. Se estima que, en conjunto, Ghana alcance el máximo nivel de pérdidas, es decir, unos 50 millones de euros anuales, cuando la liberalización arancelaria sea total, es decir, a partir de $2023^{16}$.

Los Estados pueden hacer modificaciones fiscales para intentar recuperar ingresos (por ejemplo, vía aumentos en el IVA) o disminuir gastos, pero será muy costoso en términos de bienestar social llegar a compensar todas las pérdidas y la recaudación de impuestos en África tiene serias limitaciones. Los déficits internos y comerciales, que en muchos países africanos son ya de por sí elevados, pueden aumentar de manera preocupante si no se consigue compensar la reducción de ingresos arancelarios. El caso de Ghana es algo peculiar, ya que el desarrollo del nuevo sector de los hidrocarburos puede ser una importante fuente de ingresos para el gobierno, pero como es un sector que todavía no está en la fase de comercialización, no lo tendremos en cuenta en este análisis.

\section{4. ¿Es necesario implantar los principios de no discriminación y reciprocidad en los APE?}

La respuesta a esta cuestión no está del todo clara, pero es difícil encontrar "normas escritas" que obliguen a hacerlo. En el caso de que este acuerdo se

\footnotetext{
${ }^{16}$ Según declaraciones de Dick Naezer, consejero de la Delegación de la UE en Ghana, en una entrevista concedida a IPS News en 2009.
} 
Valera, Eva. Los AAE entre la UE y África. La introducción de la reciprocidad y el caso de Ghana.

pudiera considerar un ALC, podría acogerse al art. XXIV del GATT, por el cual estarían eximidos de la observancia del principio de no discriminación frente a terceros países no ACP. A esto se oponen algunos PED, principalmente latinoamericanos, que reclaman igual trato que el resto de países ACP que no sean PMA.

El AAE no es estrictamente un ALC, ya que incorpora elementos de fomento del desarrollo económico, pero la parte meramente comercial del AAE sí cumple con los requisitos de ALC, ya que el GATT dice que "se entenderá por zona de libre comercio, un grupo de dos o más territorios aduaneros entre los cuales se eliminen los derechos de aduana y las demás reglamentaciones comerciales restrictivas (excepto, en la medida en que sea necesario, las restricciones autorizadas en virtud de los artículos XI, XII, XIII, XIV, XV y XX) con respecto a lo esencial de los intercambios comerciales de los productos originarios de los territorios constitutivos de dicha zona de libre comercio" (art. XXIV, apartado 8.b.). Asimismo, encontramos la Cláusula de Habilitación, todavía vigente, que recoge que: "Sin perjuicio de lo previsto en el Art. I del Acuerdo General, las partes contratantes pueden acordar trato diferencial $y$ más favorable a los países en desarrollo, sin tener que extender tal trato a otras partes contratantes. [Se permite] trato arancelario preferencial acordado con las partes desarrolladas para los productos originarios de los países en desarrollo, de acuerdo a los Sistemas Generalizados de Preferencias".

Por tanto, la discriminación de estos países ACP frente a los demás sí se puede mantener en cierta medida, aunque desde la OMC se pida la paulatina reducción del trato preferencial a los países que no son PMA.

En lo que se refiere a la reciprocidad, el art. XXXVI-8 especifica que "Las partes contratantes desarrolladas no esperan reciprocidad por los compromisos contraídos por ellas en negociaciones comerciales de reducir o suprimir los derechos de aduana y otros obstáculos al comercio de las partes contratantes poco desarrolladas ${ }^{17, "}$. Sin embargo, en el texto del AAE provisional entre la UE y Ghana se hace mención expresa que: "Considerando que, hasta el 31 de diciembre de 2007, las relaciones comerciales que venían manteniendo la Unión Europea y los países ACP, y que otorgaban a éstos un acceso preferente a los mercados de la UE sobre una base de no reciprocidad, no cumplían las normas de la OMC"18.

Así, el AAE no está recogiendo el art. XXXVI, e introduce una reciprocidad que, si bien reducirá el coste de las importaciones de bienes manufacturados procedentes de la UE, disminuirá considerablemente los ingresos por aranceles de los países ACP (y especialmente de los africanos).

\footnotetext{
17 Anexo I del GATT: "Se entiende que la expresión "no esperan reciprocidad" significa, de conformidad con los objetivos enunciados en este artículo, que no se deberá esperar que una parte contratante poco desarrollada aporte, en el curso de negociaciones comerciales, una contribución incompatible con las necesidades de su desarrollo, de sus finanzas y de su comercio, teniendo en cuenta la evolución anterior del intercambio comercial".

${ }^{18} \mathrm{C} 117 \mathrm{E} / 113$, que recoge el AAE provisional Ghana - UE , apartado A
} 
Valera, Eva. Los AAE entre la UE y África. La introducción de la reciprocidad y el caso de Ghana.

Más adelante en el texto del AAE provisional con Ghana se justifica la eliminación progresiva de algunos aspectos del trato preferencial de la siguiente manera: "Considerando que los sistemas comerciales preferenciales que se aplicaban anteriormente no han podido mejorar significativamente la situación económica en estos países". Por tanto, basándose en la asunción de que el comercio es la vía preferente para el desarrollo económico entendido como crecimiento, los AAE pretenden reducir y posteriormente eliminar el trato especial y diferenciado que se introdujo en el GATT allá por los años 60.

Pero esta liberalización de todos los sectores de la economía para conseguir un mayor crecimiento no se aplica a rajatabla en los países desarrollados. La UE, por ejemplo, protege sectores de su economía, como el agrícola, desde mediados del siglo XX. Mediante la Política Agraria Común (PAC), muy criticada por su coste e ineficiencia, se protege a los agricultores europeos de la competencia externa. Además, la legislación europea es cada vez más estricta en las medidas de observancia de seguridad alimentaria, respeto al medio ambiente, medidas fitosanitarias, etiquetas que indiquen el origen, etc. Estas acciones de diferenciación del producto agrícola europeo son una barrera a la entrada de productos foráneos, incluso entre los países que conforman la Unión; por tanto, aún más en el caso de productos extranjeros. Esta situación es muy preocupante para los países que compiten con los productos europeos, es decir, países del norte de África y otros como Turquía. No es tan perjudicial para los países de África Occidental, dado que los principales productos que estos exportan son tropicales, los cuales no se pueden producir en los países europeos.

Entonces, ¿cómo se justifica la 'obsesión' de la UE por introducir la reciprocidad en los $A A E$ ? Se podría deber a un cambio filosófico, a un replanteamiento teórico en el cuál se opta por desvincular la "ayuda al desarrollo" de los temas comerciales, como si el comercio libre solo pudiera tener efectos positivos, mientras que los problemas de desarrollo pudieran ser atajados residualmente mediante otras medidas como la asistencia técnica o la ayuda para llevar a cabo reformas de ajuste (fiscales, comerciales, laborales, etc.). O la respuesta puede ser otra, más pragmática: la pérdida de cuota de origen en las importaciones de Europa, en países con relativo potencial (como el caso de Ghana), es algo inaceptable, y por ello se introducen medidas relativas al comercio que puedan beneficiar a Europa.

Algo de ambas motivaciones parece que hay. En Europa se está instalando una corriente liberal que pretende desvincular o desprender al comercio de todas "sus cargas". A la vez, la pérdida de cuota es algo que no se puede aceptar, o al menos ha hecho saltar las señales de alarma.

Sea como fuere, no hay hoy en día ninguna norma escrita en la que se obligue a introducir la reciprocidad, todo son recomendaciones y declaraciones de intenciones. Pero si un gigante importador como la UE quiere que la reciprocidad sea una nueva norma en sus tratados comerciales, mucho tienen que luchar los países africanos para que no sea así. 
Valera, Eva. Los AAE entre la UE y África. La introducción de la reciprocidad y el caso de Ghana.

\subsection{Críticas generales a los AAE}

Tanto desde el mundo académico como desde las Organizaciones No Gubernamentales (ONG) y otras instituciones de desarrollo, los AAE son vistos como perjudiciales o muy perjudiciales para los países ACP, en concreto para los africanos. Así, desde ONG como Oxfam $^{19}$, se señala que los AAE son un parche de la UE para arreglar la ineficiencia del régimen de acceso preferencial de los acuerdos de Lomé, y la posibilidad de protección del $20 \%$ del mercado interno designando productos sensibles (los AAE prevén una liberalización del $90 \%$ de los intercambios entre la UE y los ACP: $100 \%$ en la UE y $80 \%$ en ACP) deja un margen de maniobra demasiado pequeño para los gobiernos de los países ACP.

Otra voz en contra es la del presidente de Senegal, Abdoulaye Wade. En una conferencia en París en el año 2007, el presidente Wade denunciaba que los AAE significaban que economías totalmente asimétricas se deberían tratar entre ellas en condiciones de competencia perfecta, así como el desmantelamiento tarifario y la abolición de otras medidas de protección. En palabras del presidente senegalés, 'se trata de consagrar como derecho un desequilibrio de hecho'. Para Wade, los AAE no se deben firmar bajo ningún concepto. 'Las economías africanas $y$ europeas son forzosamente absolutamente desiguales. Las debilidades estructurales de la industria africana no permiten una elasticidad suficiente generadora de productos de exportación. Es una cuestión de capacidad, y no de coyuntura'. Y sigue diciendo 'Aceptar los AAE, significa para nosotros liberar totalmente nuestros mercados a los productos europeos, sin esperar, como contrapartida, exportar de manera significativa al mercado europeo'. También se refirió a las enormes pérdidas en ingresos aduaneros, pérdidas que, según el presidente Wade, serían de 38.000 millones de FCFA en 2008 y llegarán a los 77.000 millones en 2015. Las medidas de compensación previstas por la UE le parecen irrisorias frente al deterioro del tejido económico que se prevé ocurra en las regiones que firmen un AAE. En la entrevista el señor Wade dice que prefiere los llamados Acuerdos de Asociación para el Desarrollo (AA) que engloban y sobrepasan el marco estrictamente comercial. Como dice, 'Desde este punto de vista, la Alianza Europa-África debería fundamentarse en una visión concreta, en la acción anticipativa $y$ no en la reacción frente a la llegada de nuevos competidores al continente africano'. Así se conseguiría que tanto Europa, algo marginada de los focos de poder (EEUU, India, China, etc.) como África, con sus problemas, luchen de manera conjunta y así poner en común tecnología y capacidad financiera europeas con el potencial capital humano y los recursos naturales africanos.

Otros académicos piden una moratoria en las negociaciones, ya que "los países africanos deben crear primero su mercado común regional antes de abrirse a la UE y a otros" (Yash Tandon ${ }^{20}$, asesor sénior del South Centre de Ginebra). Anteriormente, Ablassé Ouedraogo, anterior ministro de asuntos

\footnotetext{
${ }^{19}$ Entrevista a Carolina Doremus-Mege, responsable de Oxfam Francia. www.afrik.com, 27 de septiembre de 2007.

${ }^{20}$ Entrevista realizada el día 30 de marzo de 2010 por Patricia Handley para IPS
} 
Valera, Eva. Los AAE entre la UE y África. La introducción de la reciprocidad y el caso de Ghana.

exteriores de Burkina Faso y antiguo subdirector de la OMC, pidió que las negociaciones se suspendieran.

Vemos que el principal argumento de quienes se muestran contrarios a los AAE es la asimetría entre las partes. La UE utiliza la dependencia de la ayuda externa y del mercado europeo para presionar a los países africanos a firmar unos acuerdos injustos. Además, mantiene a los países africanos divididos y fragmentados. Hay grupos regionales, como en el de África del Sur, en el que algunos países han firmado el AAE provisional (Botswana, Lesoto, Swazilandia y Mozambique), mientras que Sudáfrica se niega, aunque de facto los productos importados por los cuatro países entraran libres a este último país mediante la Unión Aduanera de África del Sur (UAAS). Para que esto no pase, se debería desmantelar la UAAS, algo impensable y poco favorable a los intereses de la zona.

\section{Conclusiones}

La no-reciprocidad en el seno del GATT se justificaba por las diferencias entre las estructuras económicas de los distintos países que comercian en el mundo. Era una realidad en 1964 cuando lo propuso Prebisch, pero lo sigue siendo hoy en día. Los socios comerciales no se pueden tratar de igual a igual cuando existen tales niveles de asimetría. Por ello, estos acuerdos siguen bajo el paraguas del art. XXXVI, y lo único que necesita hacer la UE es no discriminar entre PED. Sin embargo, la UE también cree necesaria la observancia del principio de reciprocidad para, según ella, estar acorde con los mandatos de la OMC. El debate no está nada claro.

Por otro lado, este es el nuevo contexto en el que nos encontramos, y la mayor parte de los países ACP va a acabar firmando unos Acuerdos de Asociación Económica que, como hemos visto en el caso particular de Ghana, país altamente extravertido pero poco diversificado en su estructura exportadora, pueden significar retrocesos en el desarrollo de una estructura industrial fuerte, debido a la entrada de productos manufacturados europeos libres de aranceles y de mayor calidad. Es cierto que los bienes intermedios más baratos significan menores costes para la industria, pero si ésta es casi inexistente en los países africanos, lo único que se conseguirá es fomentar el aumento de importaciones.

Si las exportaciones aumentaran al mismo ritmo que las importaciones, el efecto podría ser incluso positivo, pero hemos visto que las exportaciones de Ghana hacia Europa están casi completamente liberalizadas, así que no es de prever un aumento del volumen y valor de éstas.

En conjunto, estos acuerdos parecen ser mucho más beneficiosos para la UE, que mantiene a la vez un discurso de liberalización del comercio a nivel mundial mientras que sigue protegiendo su agricultura, tanto de manera directa como indirecta mediante barreras no arancelarias. En las negociaciones de la OMC mantiene una postura contraria a la liberalización del sector agrícola que, aunque no afecte a países exportadores de productos tropicales, como Ghana, sí afecta a otros países ACP, ya que en los tratados bilaterales con estas 
Valera, Eva. Los AAE entre la UE y África. La introducción de la reciprocidad y el caso de Ghana.

regiones muestra exactamente la misma posición. Se habla mucho de la observancia de la reciprocidad que pide la $\mathrm{OMC}$, pero en la práctica siempre hay maneras de eludir las medidas requeridas para ello.

En todo caso, dado que la firma de estos acuerdos parece inevitable (ya se han firmado varios acuerdos provisionales a la espera de los acuerdos con las regiones), es necesaria una moratoria en las negociaciones, sin que esto suponga pérdida de preferencias para los países ACP, principalmente para los países no-PMA que no se pueden acoger al esquema EBA. En el caso de los países africanos, es necesario priorizar la armonización del sistema aduanero y ponerse de acuerdo respecto a la postura sobre normas de origen, sobre medidas de facilitación del comercio (y transporte) y sobre la mejora de las redes de comunicación e información.

Pero ese tiempo también es necesario para aumentar la capacidad productiva, para construir las bases de la industrialización de las regiones africanas. La posibilidad de esta moratoria (y una posible suspensión posterior) dependerá, en parte, de la voluntad y capacidad política de los líderes, tanto africanos como europeos, para interpretar el artículo XXXVI del GATT-OMC con un poco de libertad y así frenar la imposición de reciprocidad comercial entre la UE y las regiones africanas. La interpretación en sentido amplio o estricto será determinante a la hora de negociar una menor reciprocidad entre los países africanos y la UE.

No muestra tantos problemas, sin embargo, la no observancia del principio de no discriminación. Los AAE son claramente discriminatorios porque: i) los ACP solo conceden concesiones a la UE derivado del principio de reciprocidad; y ii) la UE todavía discrimina entre países ACP y el resto de PED. Sin embargo, la tendencia también es a la disminución de esta discriminación, debido principalmente a la presión ejercida en las negociaciones de la OMC por parte de algunos países latinoamericanos.

Por último, los países ACP, en sus diferentes grupos regionales, deberían mantenerse unidos para así poder incrementar su poder de negociación frente a la UE, pero también dentro de las negociaciones de la Ronda de Doha, en los que la agricultura está siendo un escollo para su consecución. La integración regional sería un paso positivo para conseguir mayor peso económico y político a nivel mundial.

Dados los riesgos que supone para las economías africanas, las agrupaciones de países deberían exigir una menor reciprocidad teniendo en cuenta los distintos niveles de desarrollo de las partes negociadoras. También deberían seguir luchando por la reducción drástica de la protección del mercado agrícola europeo (reforma de la PAC y eliminación de barreras no arancelarias a la entrada), una mayor compensación económica por las pérdidas en ingresos fiscales y por los costes de ajuste (que provocarán, casi con total seguridad, pérdida de puestos de trabajo) y transferencia de tecnología, entre otros aspectos. La diversificación de la estructura productiva debería ser un objetivo tanto de los gobiernos africanos como de la UE. 
Valera, Eva. Los AAE entre la UE y África. La introducción de la reciprocidad y el caso de Ghana.

\section{REFERENCIAS BIBLIOGRÁFICAS}

Atlantic Policy Congress (2002): "ACP guidelines for the negotiations of Economic Partnership Agreements". Documento de trabajo del Secretariado.

Bidaurratzaga, E. y Marín, A. (2006): "Integración regional africana y nuevas relaciones con la Unión Europea", en África en el horizonte. Introducción a la realidad socioeconómica del África Subsahariana, Instituto Universitarios de Desarrollo y Cooperación de la UCM, Catarata, pp. 201-219.

Ceara-Hatton, M. y Contreras, P. (2003): Trato especial y diferenciado desde una perspectiva histórica. Centro para el desarrollo de políticas del Caribe (CPDC), Trinidad y Tobago.

Comunidad Europea: "Partnership agreement between the members of the African, Caribbean and Pacific Group of States of the one part, and the European Community and its Member States, of the other part, signed in Cotonou on 23 June 2000". Ley 2000/483/EC.

Dosman, E. (2005): Raúl Prebisch. El Poder, los Principios y la Ética del Desarrollo BID-INTAL, Washington.

GATT (1980), Basic Instruments and Selected Documents (BISD), Suplemento № 26, pp. 203-205.

Karingi, S., Lang, R., Oulmane, N., Perez, R., Sadni Jallab, M. y Ben Hammouda, H. (2005): "Economic and welfare impacts of the EU-Africa Economic Partnership Agreements". United Nations Economic Commission for Africa.

Manchin, M. (2005): "Preference utilization and tariff reduction in European Union imports from Africa, Caribbean, and Pacific countries". World Bank Policy Research, Working Paper № 3688.

Mandelson, P. (2005): "Comunicado oficial del Comisario Europeo de Comercio sobre el APE con África Occidental". Documentos de la Comisión de Comercio Europea. Octubre. Bamako.

Oyarzun, J. (1993): "GATT, neoproteccionismo y Ronda de Uruguay", Cuaderno de Relaciones Laborales, № 2.

Oyarzun, J. (1995): "Condiciones, causas y efectos del comercio internacional", Boletín de Información Económica Española, № 2462, pp. 57-69.

Oyarzun, J. (1998): "Regionalismo versus multilateralismo: efectos de la Ronda Uruguay", en Ruesga, S., Heredero, M. I. y Fujii, G., Europa e Iberoamérica: dos escenarios de integración económica, Parteluz, Madrid, pp. 90-104.

Prebisch, R. (1964): "Towards a new trade policy for development". NNUU.

Stevens, C. y Kennan, J. (2005): "EU-ACP Economic Partnership Agreements: the Effects of Reciprocity". Institute of Development Studies IDS, Sussex.

Tetteh, H. (2011): Entrevista radiofónica realizada en citifmonline.com el 13 de enero.

UNCTAD (2009): "Handbook on duty-free, quota-free and rules of origin". Parte 1.

Wade, A. (2007): "La Alianza Europa-África. De los Acuerdos de Asociación Económica (AAE) a los Acuerdos de Asociación para el Desarrollo". Conferencia pública en la Universidad Panthéon-Assas París II. Recogida por Diouf, A. en TakingltGlobal: http://www.tigweb.org/ . 10 de noviembre de 2007. París. 
Valera, Eva. Los AAE entre la UE y África. La introducción de la reciprocidad y el caso de Ghana.

Wainio, J., Shapouri, S., Trueblood, M. y Gibson, P. (2005): "Agricultural Trade Preferences and the developing countries". Economic Research Report, №6, United States Department of Agriculture.

\section{Fuentes estadísticas:}

Eurostat, Centro Estadístico de la UE

Comext, Departamento de Agricultura, UE

Economist Intelligence Unit - Country report/briefly report

FAO Country Stats

UN Comtrade

UNCTAD 
Valera, Eva. Los AAE entre la UE y África. La introducción de la reciprocidad y el caso de Ghana.

\section{ANEXOS}

Glosario terminológico:

AAE - Acuerdos de Asociación Económica

ACP - África, Caribe y Pacífico

AGOA - African Growth and Opportunity Act

ALC - Área de Libre Comercio

ASS - África Sub-Sahariana

BM - Banco Mundial

CEDEAO (ECOWAS) - Comunidad Econ. de los Estados de África

Occidental

CEE - Comunidad Económica Europea

EBA - Everything But Arms

FED - Fondo Europeo de Desarrollo

GATT - General Agreement on Trade and Tariffs

IED - Inversión Extranjera Directa

NMF - Nación Más Favorecida

OMC - Organización Mundial del Comercio

ONG - Organización No Gubernamental

PAC - Política Agraria Común

PD - Países Desarrollados

PED - Países En Desarrollo

PMA - País Menos Adelantado

SPG - Sistemas de Preferencias Generalizados

UA - Unión Aduanera

UE - Unión Europea

UEMOA - Unión Económica y Monetaria de África Occidental

UNCTAD - United Nations Conference on Trade and Development

TABLA 1. LISTA DE PaÍSES PMA

\section{PAÍSES MENOS ADELANTADOS (PMA) de África, Caribe y Pacífico (ACP)}

\begin{tabular}{cccccc} 
& & África & & Caribe & $\underline{\text { Pacífico }}$ \\
Angola & Gambia & Mauritania & Somalia & Haití & Islas Salomón \\
Benín & Guinea & Mozambique & Sudán & \\
Burkina Faso & Guinea Bissau & Níger & Tanzania & \\
Burundi & Guinea Ecuatorial & R.D. Congo & Togo & Samoa \\
Chad & Lesotho & R. Centroafricana & Uganda \\
Comores & Liberia & Ruanda & Zambia \\
Djibuti & Madagascar & S. Tomé y Príncipe & \\
Eritrea & Malawi & Senegal & Tuvalu \\
Etiopía & Malí & Sierra Leona & \\
\hline
\end{tabular}

Fuente: ONU 
Valera, Eva. Los AAE entre la UE y África. La introducción de la reciprocidad y el caso de Ghana.

TABLA 2. Aranceles a los QUe Se enfrentan Las exportaciones de Ghana (2007)
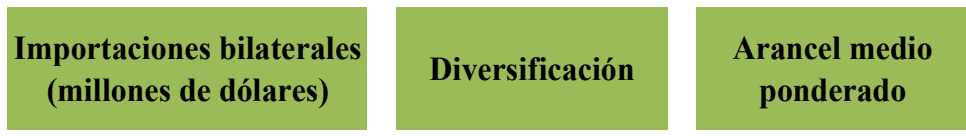

Productos agrícolas

Comunidades Europeas

Japón

Malasia

Estados Unidos

India

Productos no agrícolas

Comunidades Europeas

Ucrania

Estados Unidos

Hong Kong

India

1.232
121
116
56
55

289

215

109

89

76

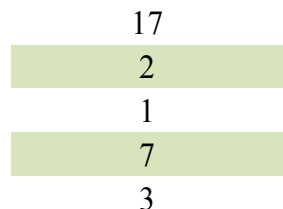

\begin{tabular}{|c|c|}
\hline 4,5 \\
\hline 0,2 \\
\hline 0,1 \\
\hline 0,6 \\
\hline 19,7 \\
\hline
\end{tabular}

\begin{tabular}{|c|}
97,1 \\
95,8 \\
99,7 \\
100,0 \\
34,0
\end{tabular}

2,2

2,0

1,6

0,0

5,4
Importaciones libres de aranceles (valor en \%)

Notas: India 2006; "Diversificación" como número de líneas arancelarias (6 dígitos) que representan el 95\% del comercio

Fuente: Tariff profiles 2009, OMC

Tabla 3. ARANCELES a La importación en La UE y en GHANA

\begin{tabular}{|c|c|c|c|c|c|c|c|c|c|c|}
\hline & \multicolumn{6}{|c|}{ Aranceles NMF } & \multicolumn{4}{|c|}{ Importaciones } \\
\hline & \multicolumn{2}{|c|}{ Arancel medio } & \multicolumn{2}{|c|}{ Libre de aranceles (\%) } & \multicolumn{2}{|c|}{ Máximo } & \multicolumn{2}{|c|}{ Porcentaje } & \multicolumn{2}{|c|}{ Libre de aranceles $(\%)$} \\
\hline & $\mathbf{U E}$ & Ghana & $\mathbf{U E}$ & Ghana & UE & Ghana & $\mathbf{U E}$ & Ghana & $\mathbf{U E}$ & Ghana \\
\hline Productos animales & 27,6 & 19,6 & 23,8 & 2,2 & 236 & 20 & 0,2 & 1,3 & 25,3 & 3,1 \\
\hline Productos lácteos & 64,1 & 20,0 & 0,0 & 0,0 & 205 & 20 & 0,0 & 0,8 & 0,0 & 0,0 \\
\hline Frutas, vegetales, plantas & 12,4 & 18,9 & 18,6 & 0,5 & 233 & 20 & 1,0 & 0,9 & 17,5 & 0,0 \\
\hline Café, té & 7,2 & 20,0 & 27,1 & 0,0 & 99 & 20 & 0,7 & 0,1 & 83,4 & 0,0 \\
\hline Cereales y preparaciones & 22,3 & 17,8 & 7,2 & 3,8 & 123 & 20 & 0,1 & 4,9 & 6,7 & 1,1 \\
\hline Oleaginosas, grasas y aceites & 6,4 & 14,7 & 43,4 & 0,0 & 180 & 20 & 1,2 & 1,0 & 69,7 & 0,0 \\
\hline Azúcar y dulces & 33,3 & 11,3 & 0,0 & 0,0 & 143 & 20 & 0,0 & 1,7 & 0,0 & 0,0 \\
\hline Bebidas y tabaco & 20,7 & 19,9 & 19,8 & 0,0 & 203 & 20 & 0,4 & 0,9 & 23,9 & 0,0 \\
\hline Algodón & 0,0 & 10,0 & 100,0 & 0,0 & 0 & 10 & 0,0 & 0,0 & 100,0 & 0,0 \\
\hline Otros productos agrícolas & 5,8 & 14,5 & 65,5 & 9,3 & 133 & 20 & 0,4 & 0,3 & 70,6 & 28,8 \\
\hline Pescado y derivados & 11,8 & 11,1 & 9,0 & 0,0 & 26 & 20 & 1,3 & 2,3 & 5,1 & 0,0 \\
\hline Minerales y metales & 2,0 & 12,2 & 49,2 & 4,3 & 12 & 20 & 18,0 & 13,1 & 59,4 & 6,3 \\
\hline Petróleo & 3,1 & 7,0 & 20,0 & 20,0 & 5 & 10 & 18,9 & 12,7 & 83,8 & 96,3 \\
\hline Químicos & 4,6 & 11,8 & 21,4 & 0,6 & 7 & 20 & 9,2 & 10,8 & 43,1 & 9,4 \\
\hline Madera, papel, etc. & 0,9 & 16,1 & 81,2 & 11,2 & 10 & 20 & 3,3 & 6,5 & 85,0 & 69,7 \\
\hline Textiles & 6,6 & 16,9 & 2,1 & 0,6 & 12 & 20 & 2,4 & 3,1 & 2,0 & 10,2 \\
\hline Confección & 11,5 & 20,0 & 0,0 & 0,0 & 12 & 20 & 4,4 & 0,5 & 0,0 & 0,0 \\
\hline Piel, zapatos, etc. & 4,2 & 14,2 & 22,7 & 0,6 & 17 & 20 & 2,4 & 2,9 & 17,0 & 0,1 \\
\hline Maquinaria no-eléctrica & 1,9 & 2,7 & 21,0 & 76,3 & 10 & 20 & 12,3 & 10,6 & 54,7 & 70,7 \\
\hline Maquinaria eléctrica & 2,8 & 10,1 & 20,1 & 15,0 & 14 & 20 & 11,5 & 8,3 & 54,8 & 16,9 \\
\hline Equipamiento de transporte & 4,3 & 6,1 & 12,5 & 45,6 & 22 & 20 & 5,5 & 15,1 & 10,8 & 9,2 \\
\hline Manufacturas & 2,7 & 15,0 & 20,6 & 7,5 & 14 & 20 & 6,7 & 2,2 & 52,7 & 2,6 \\
\hline
\end{tabular}

Fuente de los datos: Tariff profiles 2009, OMC 